\title{
The Experimental Study on Promoting the Ilizarov Distraction Osteogenesis by the Injection of Liquid Alg/nHAC Biocomposites
}

\author{
Xinhui Liu, ${ }_{1}^{1}$ Di Yu, ${ }^{1}$ Jieyan Xu, ${ }^{1}$ Chao Zhu, ${ }^{1}$ Qingling Feng, ${ }^{2}$ Chuanyong Hou, \\ Hua Wang, ${ }^{1}$ Yelin Yang, ${ }^{1}$ and Guoping Guan ${ }^{1}$ \\ ${ }^{1}$ Orthopaedics, The Affiliated Jiangning Hospital of Nanjing Medical University, Nanjing 211100, China \\ ${ }^{2}$ State Key Laboratory of New Ceramic and Fine Processing, Tsinghua University, Beijing 100084, China
}

Correspondence should be addressed to Xinhui Liu; professorlxh2008@163.com

Received 7 February 2014; Accepted 7 March 2014; Published 14 April 2014

Academic Editor: Xiaoming Li

Copyright (c) 2014 Xinhui Liu et al. This is an open access article distributed under the Creative Commons Attribution License, which permits unrestricted use, distribution, and reproduction in any medium, provided the original work is properly cited.

Limb lengthening is frequently utilized in treating limb length inequalities, angulation deformities, nonunions, complex fractures, and deficiencies after tumor resection in more recent year. The procedure of limb lengthening pioneered by Ilizarov is now a widely accepted method for correcting limb length inequality and short stature as well as for bridging large defects in long bones. In order to promote bone healing during distraction osteogenesis and reduce the complications caused by limb lengthening pioneered, an alginate/nanohydroxyapatite/collagen (Alg/nHAC) composite was fabricated. General observation, histologically morphological observations, X-ray examination, biomechanical test, bone density, and the percentage area of bone trabecula were used to assay the ability of $\mathrm{Alg} / \mathrm{nHAC}$ composite to promote bone healing. The present study demonstrates that the injection of liquid $\mathrm{Alg} / \mathrm{nHAC}$ composites can significantly promote distraction osteogenesis. Alg/nHAC composite is promising for clinical application, solving the healing problem of backbone osteotomy and the fixing problem of metaphyseal backbone.

\section{Introduction}

Corrective limb lengthening is frequently utilized in treating limb length inequalities, angulation deformities, nonunions, complex fractures, deficiencies after tumor resection, and, in more recent years, persons of short stature. During the last two decades, many developments were achieved in the field of limb lengthening surgery, in which the main goal was to increase patients' acceptance and comfort during lengthening [1]. Among them, the adaptation of bone during distraction osteogenesis (DO) is reliable and predictable [2], which is a surgical procedure used to promote tissue regeneration in long bones. It is used to lengthen limbs, repair major bone defects caused by infections or tumours, and correct congenital or acquired craniofacial defects $[3,4]$.

The procedure of limb lengthening pioneered by Ilizarov is now an accepted method for correcting limb length inequality and short stature as well as for bridging large defects in long bones. Limb lengthening is associated with numerous complications: infections $[5,6]$, stiff joints $[6,7]$, pseudarthrosis [6-8], early union $[7,8]$, and neurological sequela [7-9]. The bone healing problems associated with the other methods of limb lengthening have largely been resolved. Even though external systems have been improved over the years, problems with soft tissue transfixation, neurovascular injuries, pin track infections, malalignment, joint stiffness, pain, and poor cosmetic results are still frequent $[10,11]$. A further study about lengthening is necessary.

Along with the development of tissue engineering, bone tissue engineering was applied to treat bone defect. Large amounts of material systems have been developed to mimic the natural extracellular matrix (ECM) and induce bone formation [12-15]. Researches had demonstrated that nHA had ability to promote ossification and bone regeneration [16-19] and collagen was a natural polymer with excellent biocompatibility and bioactivity [20-24]. The combination of bone tissue engineering and DO technology is promising. In this research, a liquid Alg/nHAC composite was injected into 
the extension area of rabbits' tibia to study the effect on bone healing.

\section{Materials and Methods}

2.1. Materials. Acid-soluble type I collagen gel (solid content: 1\%) was produced by Beihua Fine Chemicals Co., Ltd., Beijing. Sodium phosphate and calcium sulfate were produced by Yili Fine Chemicals Co., Ltd., Beijing. Sodium alginate was produced by Guoyao Chemical Reagent Co., Ltd. Calcium carbonate was produced by Beijing Modern Oriental Fine Chemicals Co., Ltd. Kirschner wire $(12 \mathrm{~mm})$ was produced by Jinlu Medical Equipment Company, Jiangsu. The New Zealand rabbits were obtained from laboratory animal center of Hebei Medical University.

2.2. Equipment. Philips 500mAX film machine (Germany), IPP (Image-Pro Plus IPP) Mediaplayer (USA), DEXAUNIT2000 dual-energy X-ray absorptiometry instrument (Beijing, China), USS biomechanical testing machine (Shenyang, China), automatic dehydrator TP1020 (Germany), slicer 2125 (Germany), automatic paraffin embedding machine TKYBM (Hubei, China), roast machine HI1220 (Germany), pushing machine HI1210 (Germany), Olympus camera binocular microscope CX31 (Japan), and image analysis system (Beijing, China) were used in this research.

\subsection{Methods}

2.3.1. Preparation of $A l g / n H A C$. A small amount of sodium alginate was mixed with sodium alginate $\left(\mathrm{Na}_{3} \mathrm{PO}_{4} \cdot 12 \mathrm{H}_{2} \mathrm{O}\right)$ and dissolved in deionized water. After stirring for $20 \mathrm{~min}$ utes, a pale yellow aqueous solution of completely dissolved alginate was obtained. Calcium sulfate and deionized water were mixed in a beaker according to the setting proportion to obtain a slurry of calcium sulphate. The slurry was stirred until no significant particles can be seen and then kept more than $24 \mathrm{~h}$ to remove static. A certain amount of bone meal (nHAC) which was prepared according to the research of Li et al. [25] was dissolved in water and stirred to obtain sufficient bone paste. Then, the bone paste was mixed with the aqueous solution of sodium alginate and stirred to produce an intermixture. Next, the slurry of calcium sulphate was mixed with the intermixture and stirred to obtain a new intermixture. The new obtained intermixture was kept alone for about $15 \mathrm{~min}$. The solid bone repair materials were got after the internal situ crosslinking reaction. Finally, the materials were sterilized with Co60 irradiation (2.5 Mrad) for the next experiments.

2.3.2. Manufacture of External Fixation Devices. In the experiment, we made use of self-made and improved Ilizarov full-ring external fixation with an outer diameter of $90 \mathrm{~mm}$, an insider diameter of $60 \mathrm{~mm}$, thickness of $4 \mathrm{~mm}$, and 14 holes through the ring. The diameter of each is $6.5 \mathrm{~mm}$. The diameter of each screw rod is $6 \mathrm{~mm}$ and the length is $105 \mathrm{~mm}$. The screw pitch is $1 \mathrm{~mm} / \mathrm{lap}$, so $1 \mathrm{~mm}$ extension length can be achieved by extending one lap of the screw rod. The fixed needle is medical Klinefelter needle with diameter of $1.2 \mathrm{~mm}$ and $1.0 \mathrm{~mm}$, respectively.

2.3.3. The Preparation of Animal Model of Rabbit Tibia Limbs' Elongation. We selected big-ear white New Zealand rabbits $(2-2.5 \mathrm{Kg})$ as the experimental animal. The rabbits were banned from food intake before operation and their left hind shins were reserved. Then we anaesthetized the rabbits by intravenous injection of $1 \%$ pentobarbital sodium after that disinfected the bed sheets and put the rabbit back on the rabbit platform. We drilled two $1.2 \mathrm{~mm}$ Kirschner wires across in the location $1.0 \mathrm{~cm}$ above tubercles of tibia. A ring of preassembled external fixation was installed and the Kirschner wire would be fixed on the steel ring. Two $1.0 \mathrm{~mm}$ Kirschner wires were drilled across in the distal of tubercles of tibia in order to correspond with proximal Kirschner wire, and the steel needle would be fixed on the steel ring using screw bolt meanwhile. Adjust external fixation to be firm and parallel. Under aseptic conditions, we made anterior lateral tibial longitudinal incision which was as deep as periosteum between the upper and lower two sets of needles. Moreover, the incision was peeled in the periosteum and the upper tibial appeared. Pry the lower end of the fibula into two parts and truncate tibia fully in tubercles of tibia by fretsaw. Adjust external fixation to make two ends of the fracture close and keep the anatomical paraposition. Then tighten all the nuts in order to avoid any accidental. Wash the wound and close the incision after the suture of periosteum. To prevent infection, making penicillin $400000 \mathrm{U}$ intramuscular injection for 5 days is necessary after operation. We should make an Anerdian wet compress on the blade and needle tract at the same time. It started to extend at the speed of $1 \mathrm{~mm} /$ day after 5 days of operation. Finally, it would extend $20 \mathrm{~mm}$ by 2 times in 20 days. It should be kept fixed for 9 weeks after lengthening. Raise the rabbits under the same conditions, and the rabbits are free to move in the cage. Rabbits were executed at particular period and the specimens were obtained. The animal model of rabbit tibia elongation was shown in Figure 1.

2.3.4. Animal Grouping. 60 New Zealand rabbits $(2-2.5 \mathrm{Kg})$ were classified into two groups equally, namely, group A and group B. After the end of the extension, liquid Alg/nHAC was injected into rabbits of group $\mathrm{A}$ in the region of elongation. Rabbits of group B were not given any treatment as control. Groups A and B were molded and raised under the same conditions and the rabbits are free to move in the cage. Rabbits were executed at particular period and obtained the specimen.

\subsection{Observations and Tests}

2.4.1. General Observation. The general observation should include the following contents: the conditions of postoperative wound healing, daily activities of rabbits, and general bone formation of specimens in the extension area and whether the needle track was infected. 


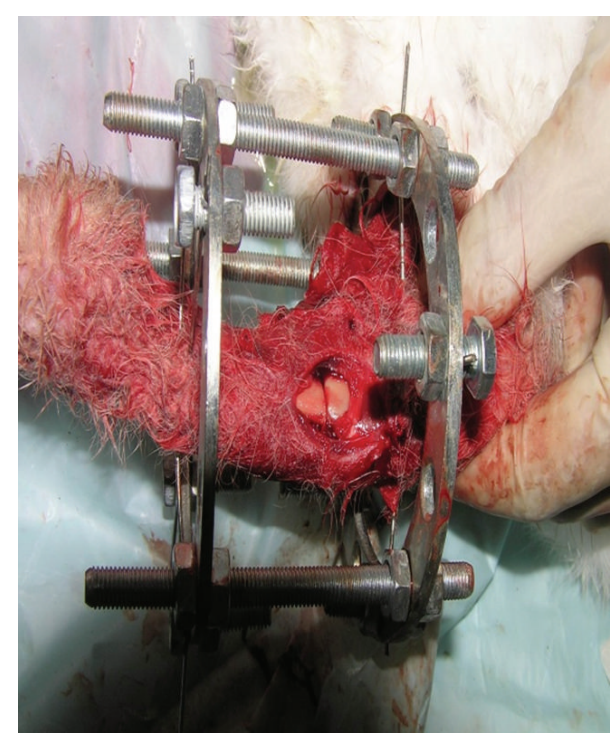

(a)

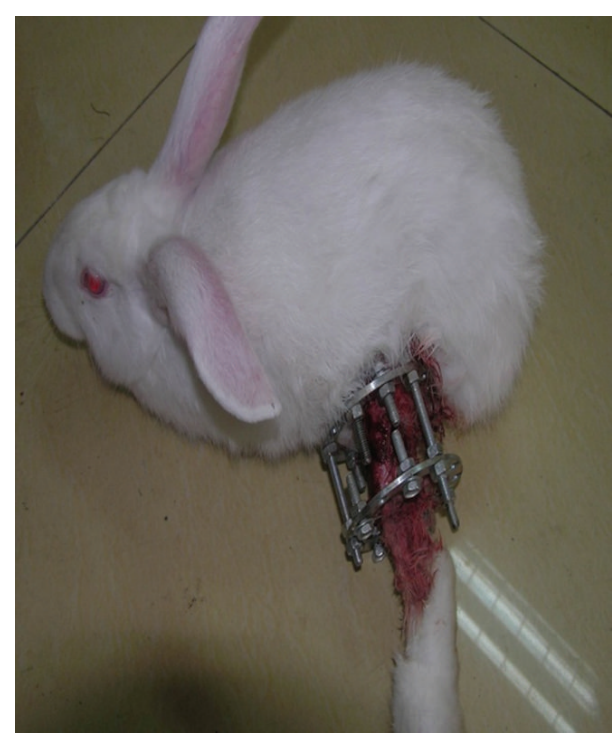

(b)

FIGURE 1: The animal model of rabbit tibia elongation ((a) osteotomy in the tibia and (b) the situation of rabbit after the osteotomy surgery).

2.4.2. Histological Observation. We executed rabbits and acquired specimens at the following periods: medium term of bone elongation, termination of bone elongation at 2, 4, and 8 weeks after termination of bone elongation, respectively. The acquired specimens were fixed by $10 \%$ formaldehyde, and ossified specimens were decalcified for 2 weeks. Then we embedded sections by paraffin, conducted HE staining, and made an observation under light microscope after fixing sections.

2.4.3. X-Ray Observation. We took photos of bone elongation at three periods, respectively: after operation, termination of bone elongation, and 2, 4, and 8 weeks after termination of bone elongation. By means of these photos in different periods, we could observe the condition of bone formation of extended position and formation of poroma. The camera model was Philips 500mAX, and conditions of exposure were $50 \mathrm{KV}, 4 \mathrm{~ms}$.

\subsubsection{Measurement of the Percentage Area of Bone Trabec-} ula. We observed the tissue slices under the microscope and acquired images and measured the percentage area of trabecular bone using IPP (Image-Pro Plus IPP) Mediaplayer measurement software.

2.4.5. Bone Density Test. Five rabbits were killed in each group for obtaining the samples after 8 weeks, five rabbits were killed in each group to obtain the samples of termination of bone elongation. We determined the bone density using dual-energy X-ray bone densometer.

2.4.6. Biomechanical Test. Three-point bending experiment was conducted in elongation area of rabbit tibia at 2, 4, and 8 weeks, respectively. Five specimens in each group (groups $\mathrm{A}$ and $\mathrm{B}$ ) were prepared at each period and 5 specimens from normal contralateral tibia were obtained and set as control group. For the specimens, intermediate point was support point and both ends were fixed with a span of $30 \mathrm{~mm}$. Then a loading was imposed slowly at the constant speed of $0.5 \mathrm{~mm} / \mathrm{min}$ until specimens fractured. The average stress value was taken and compared with the maximum stress value of each group.

2.4.7. Statistical Methods. All acquired data were statistically analyzed by statistical software SPSS10.0.

\section{Results}

3.1. General Observation. The rabbits had regular diet and normal activities after operation. Affected limbs were slightly swelled, the swelling would be reduced in 1-2 weeks, and all the incisions would also be healed normally. In the course of experiment, 15 rabbits died because of diarrhea and 2 rabbits fractured in the Kirschner wire fixation. Except the rabbits mentioned above, which were excluded in this experiment, all the other rabbits survived. External fixation was fixed so reliably that it made no adverse effects to animals. We acquired 3 specimens after termination of bone elongation. Via the observation of elongation region, dense fibrous connective tissue was found in the region of elongation, and the material quality was soft and tough without the appearance of ossification.

Five rabbits of each group were executed, and a total of 10 rabbits were put to death for obtaining specimens after 2 weeks of termination of bone elongation. Most of the elongation region in group A was ossified, and it was difficult to cut poroma using operating knife blade. As to group B, elongation region was ossified slightly; however, a majority of fibrous connective tissue still existed.

Five rabbits of each group were executed, and a total of 10 rabbits were put to death for obtaining specimens after 


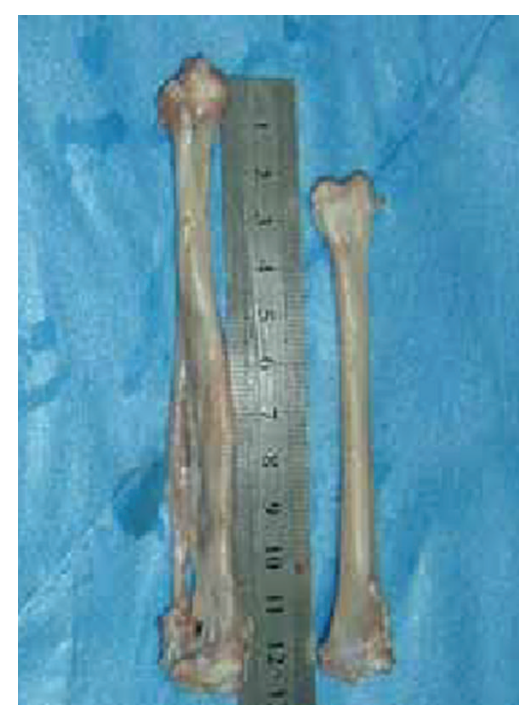

Figure 2: Compared with uninjured lateral tibia (right), operation side lateral tibia (left) extended $2 \mathrm{~cm}$.

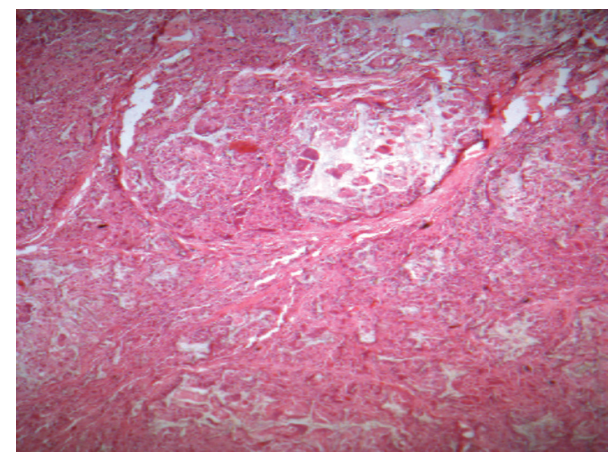

FIGURE 3: Histologically morphological observations of the extension area in medium item. The extension area was filled with dense fibrous connective tissue and no osteogenesis can be seen.

4 weeks of termination of bone elongation. For group A, elongation region was totally ossified, but the intensity of elongation region was weaker than the uninjured side and it could be broken easily. As to group B, elongation region was ossified basically, and the intensity of callus was not high and it was practicable to cut using operating knife blade.

Five rabbits of each group were executed, and a total of 10 rabbits were put to death for obtaining specimens after 8 weeks of termination of bone elongation. The elongation regions of groups A and B were ossified entirely. The appearance of group A was similar to normal bone and it was very hard to fracture, while group B was prone to fracture. Compared with uninjured lateral tibia, operation side lateral tibia extended $2 \mathrm{~cm}$ (Figure 2).

\subsection{Histologically Morphological Observations. Five rabbits} were killed at each medium term and termination of elongation, respectively, and a total of 10 rabbits were killed for obtaining specimens. The elongation region was filled with dense fibrous connective tissue, and bone tissues were not found (Figure 3).
Five rabbits of each group were executed and a total of 10 rabbits were put to death for obtaining specimens after 2 weeks of termination of bone elongation. The material implanted into group A was separated by fibrous connective tissue; fibrous connective tissue and blood vessel grew into the transplanted material. Osteoid formation mainly comprised of fibrous callus could be seen in most of the material, but a few osseous calluses appeared around separated materials (Figure 4).

Five rabbits were executed and a total of 10 rabbits were put to death for obtaining specimens after 4 weeks of termination of bone elongation. For group A, most mature bone could be seen, bone lacuna and the amount of endoskeleton cells increased obviously, and transplanted materials decreased obviously (Figure $5(\mathrm{a})$ ). For group B, lots of osteoid appeared, woven bone was formed, and trabecular bone got mature gradually; part of osteoblast grew into osteocyte gradually, trabecular bone increased compared to 2 weeks of termination of bone elongation, and immature trabecular bones were still in the the major (Figure 5(b)).

Five rabbits of each group were executed and a total of 10 rabbits were put to death for obtaining specimens after 8 weeks of termination of bone elongation. As to group A, injected material disappeared basically, only very small amount of material existed in the center, and massive mature bony callus was formed (Figure 6(a)). As to group B, generous fibrous callus and bony callus accounted for the bulk, and a few mature bone lacuna and osteocyte emerged (Figure 6(b)).

3.3. X-Ray Examination. The X-ray examination after the surgery showed that the tibial osteotomy is complete, the fibula is also disconnected, and the site and lines of the osteotomy are well matched (Figure 7(a)). The X-ray examination done at 10 days after surgery showed that the tibial osteotomy had been apart and the line of osteotomy matched well (Figure 7(b)). The X-ray examination done after lengthening showed that a range about $2 \mathrm{~cm}$ existed and the line of osteotomy matched well. The extended area was of low density development and no calcification could be observed (Figure 7(c)). Besides, the Alg/NHAC used in group A, which is a liquid injection, is also of low density development (Figure $7(\mathrm{~d})$ ).

At 2 weeks after lengthening, large amounts of high density development formed and filled in the extension area in group A (Figure 8(a)). A small amount of high density development could be observed, namely, a few of new bones formed in group B (Figure 8(b)). At 4 weeks after the lengthening, the high density development in extension area of group A obviously increased (Figure 8(c)). The callus volume of group B increased when compared to group B at two weeks but less than group $A$ at the same period (Figure $8(d)$ ). At 8 weeks after lengthening, X-ray examination showed that the imaging performance of group A had been close to normal bone, with a connected marrow and similar bone density between cortical bone of extension area and normal bone upper and lower (Figure 8(e)). The elongation areas were all ossification in group $\mathrm{B}$, but the bone mineral densities were lower and bone masses were less (Figure 8(f)). 


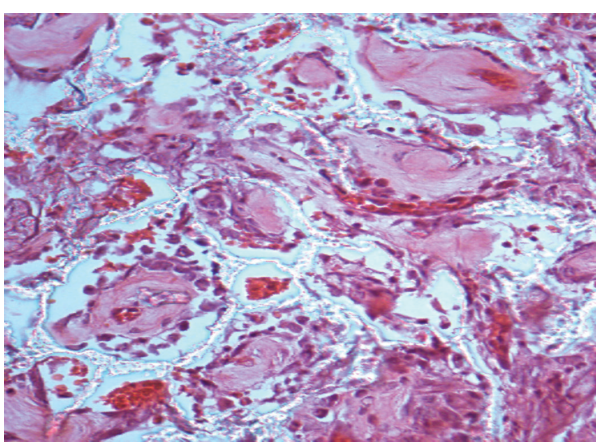

(a)

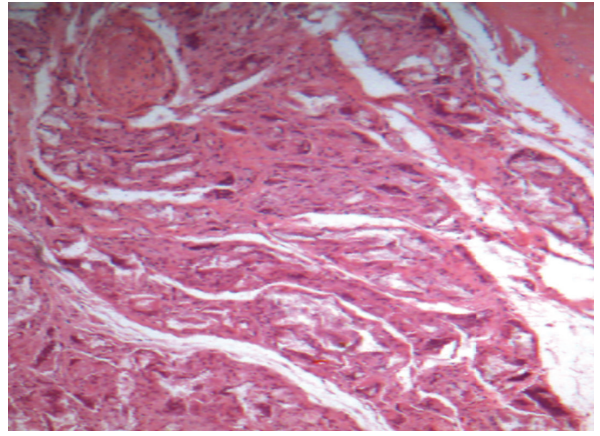

(b)

FiguRE 4: In the first two weeks after the end of the extension, in group A, osteoid based on fibrous callus can be seen in most of the materials (a); in group B, large amounts of fibrous connective tissue can be seen and there is a small amount of osteoid formation (b).

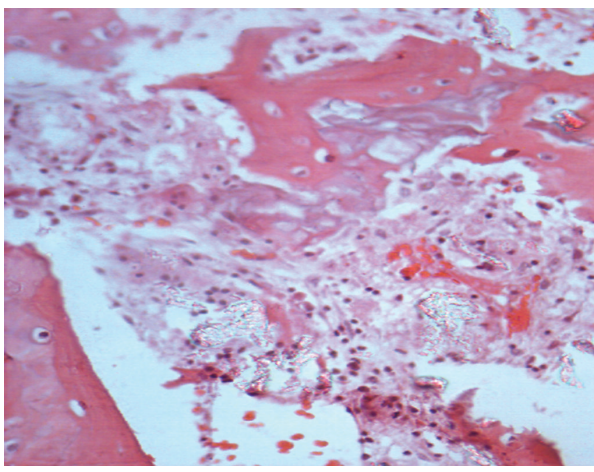

(a)

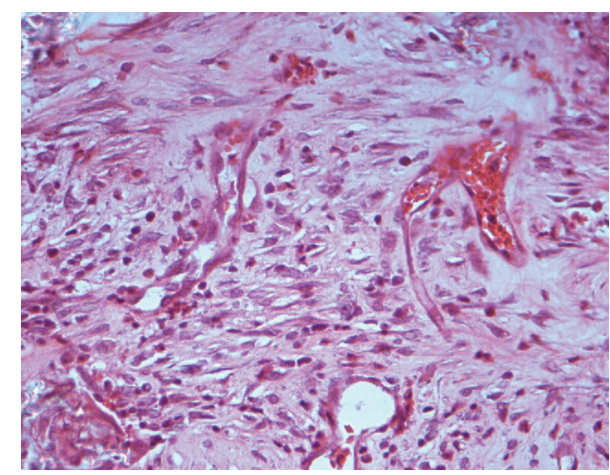

(b)

Figure 5: In the first four weeks after the end of the extension: (a) the histologically morphological observations of the extension area of group A and (b) the histologically morphological observations of the extension area of group B.

3.4. Measurement of the Percentage Area of Trabecular Bone. 30 specimens were obtained by three times, of which, 10 specimens (group A: 5, group B: 5) were obtained at week 2, 8 specimens (group A: 5, group B: 5) were obtained at week 4, and the last 10 specimens (group A: 5, group B: 5) were obtained at week 8 .

The statistical analysis showed that the percentage areas of the two groups were significantly different in 2,4 , and 8 weeks, $P<0.05$. The percentage area of trabecular bone in group A was significantly higher than in group B, as shown in Table 1.

3.5. Measurement of the Bone Density. In this study, 13 specimens were obtained: (group A: 6, group B: 7) at week 8 . The contralateral normal tibial bone was set as group $\mathrm{C}$ and measured.

BMD of groups $\mathrm{A}, \mathrm{B}$, and $\mathrm{C}$ was $(0.1240 \pm 0.0069)$, $(0.0873 \pm 0.0042)$, and $(0.1771 \pm 0.0078)$ separately. The BMD of group $\mathrm{A}$ is higher than group $\mathrm{B}$, and a significant difference existed $(P<0.01)$ at week 8 .

The bone density in group A was to recover to 70.29 percent when compared to normal bone, while that of group $\mathrm{B}$ was to recover to $49.29 \%$. There was a significant difference $(P<0.01)$ between the two groups.
TABle 1: Percentage area of trabecular bone in two groups at 2, 4, and 8 weeks $(\bar{x} \pm s)$.

\begin{tabular}{lccc}
\hline & $2 \mathrm{w}$ & $4 \mathrm{w}$ & $8 \mathrm{w}$ \\
\hline Group A & $4.51 \pm 1.83$ & $18.68 \pm 3.77$ & $33.11 \pm 4.11$ \\
Group B & $11.2 \pm 2.01$ & $32.42 \pm 2.88$ & $51.49 \pm 9.28$
\end{tabular}

3.6. Biomechanical Test. In this test, 13 specimens were obtained: (group A: 6, group B: 7) at week 8. Five contralateral normal tibial bones were set as group $\mathrm{C}$ and measured.

The maximum bending stress in groups $\mathrm{A}, \mathrm{B}$, and $\mathrm{C}$ was $(273.524 \pm 50.680) \mathrm{N},(132.471 \pm 37.010) \mathrm{N}$, and $(396.570 \pm$ 45.121) N separately.

The maximum bending stress of group $\mathrm{A}$ is higher than that of group B at week 8 , and a significant difference $(P<$ 0.01 ) existed. The biomechanical property of group A was to recover $68.94 \%$, while that of group B was to recover $33.33 \%$. There was a significant difference $(P<0.01)$ between the two groups.

\section{Discussion}

Although the Ilizarov method is regarded as a revolution in the history of orthopedic therapeutics, the bone healing 


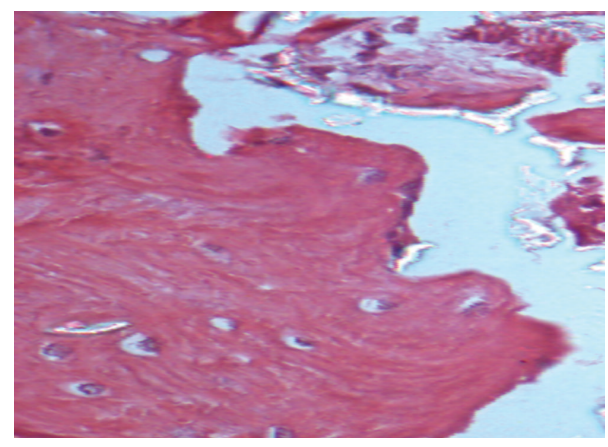

(a)

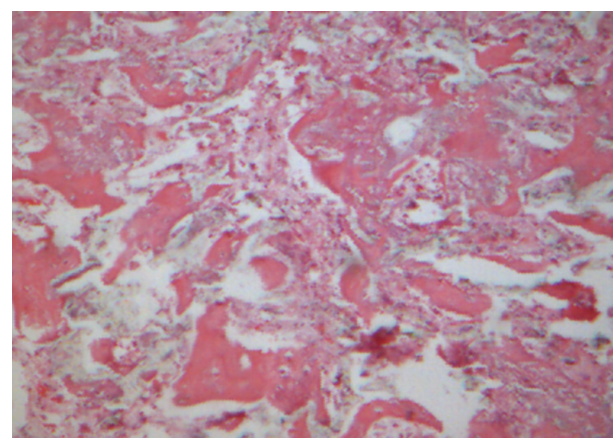

(b)

Figure 6: In the first eight weeks after the end of the extension: (a) the histologically morphological observations of the extension area of group A and (b) the histologically morphological observations of the extension area of group B.

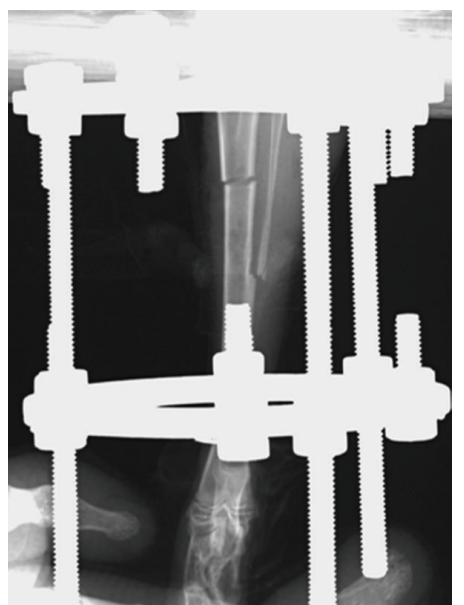

(a)

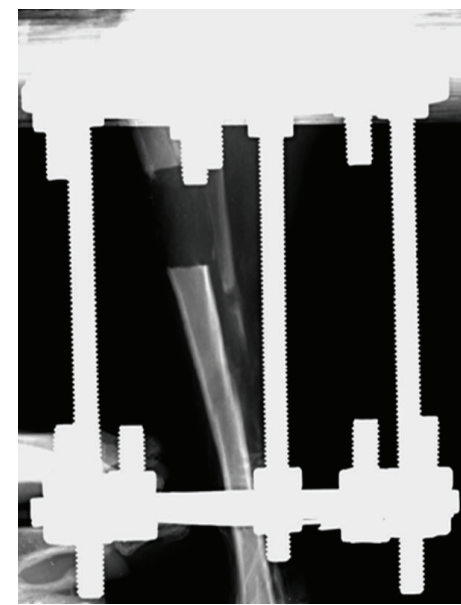

(c)

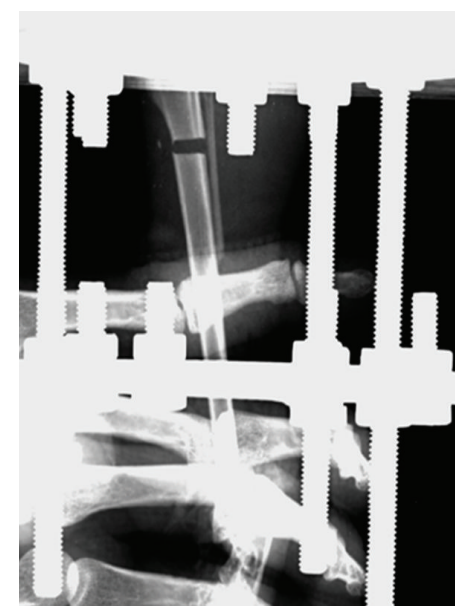

(b)

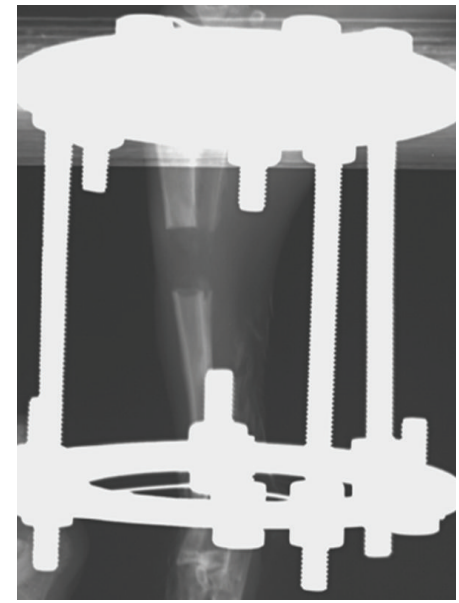

(d)

FIGURE 7: The X-ray image of rabbit tibia of different group immediately taken after the surgery.

is relatively slow and there are more complications existing. Besides, the pull speed can just be $1.0 \mathrm{~mm}$ a day, considering the bone healing time of extended area, and each extension of $1.0 \mathrm{~mm}$ needs about one or two months [26]. Therefore, many scholars have explored the mechanism and method to promote bone healing. The biological mechanism of limb lengthening was regarded as osteotylus lengthening. Ilizarov [27] has described the biological characteristics of broken ends of fractured bone in the traction state. It was discovered that the connection of the collagen fibers in bone gap and 


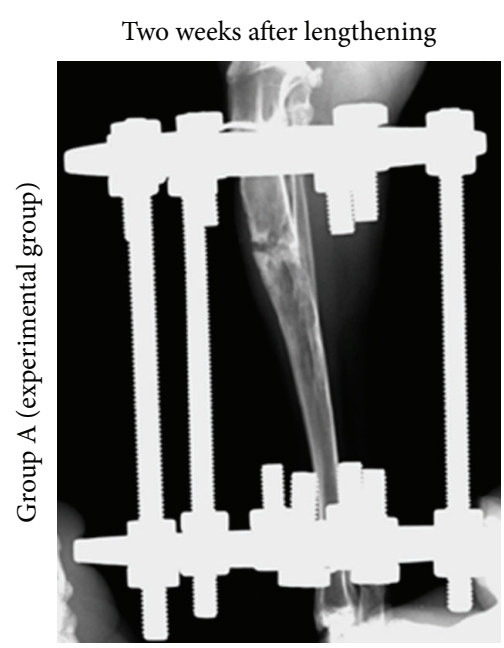

(a)

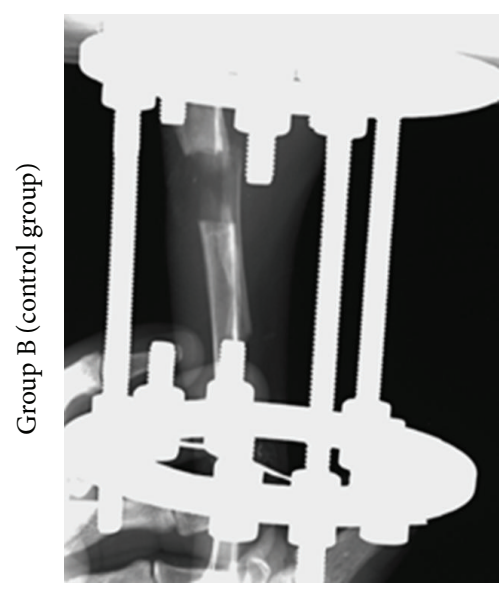

(b)

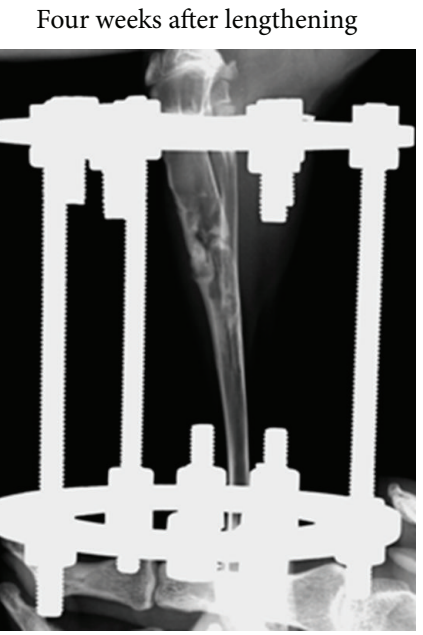

(c)

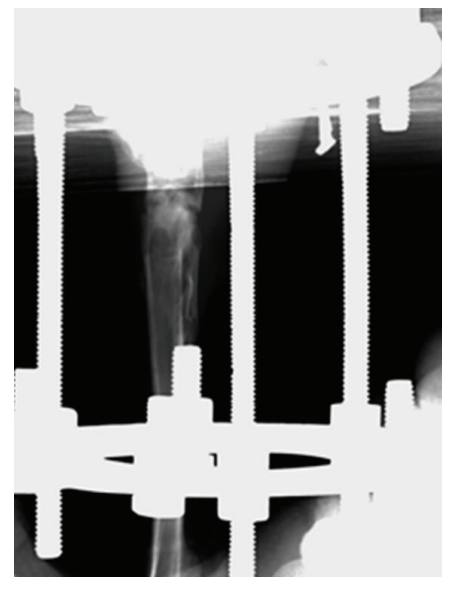

(d)

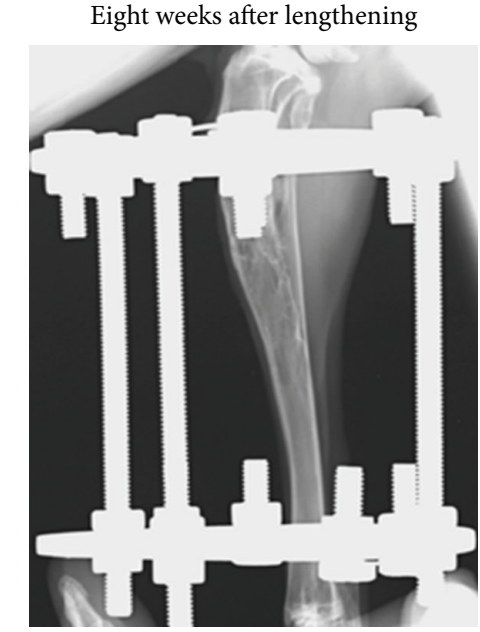

(e)

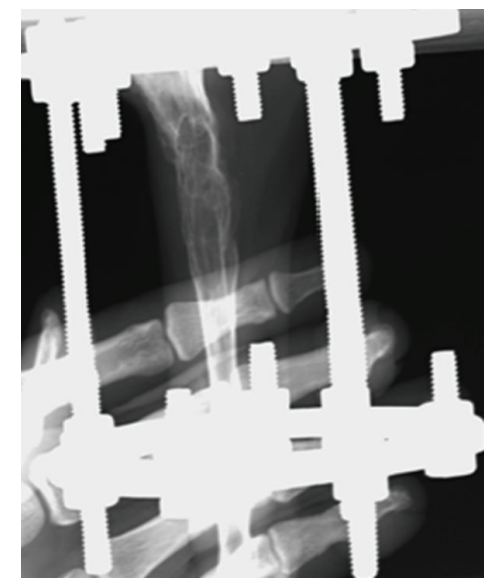

(f)

FIGURE 8: The X-ray image of rabbit tibia in different group at different time after lengthening.

the fusion of the trabecular of new bone were an ongoing repair process which contained new bone formation and the translation of matrix to matrix. In the extension of the human tibia, cancellous bone and bundle bone were clearly observed and finally turned to osteocyte, which was a process that looked like fetal growth and development. The discovery of tumor-related gene c-fos and c-jun in the early stages of limb lengthening, which was related to the fetal development, further proved the theory that distraction osteogenesis can make some process that usually took place in the stage of fatal development repeat in adult tissue.

The biological theory of distraction-traction osteogenesis (DO) offered the theory support for limb lengthening and changed the biological mechanism of limb lengthening. The application of DO concept significantly improved the quality of bone growth and reduced incidence of nonunion complications. Limb lengthening was not just a simple extension of bone length, but the interaction of bone, soft tissue, joint, and systemic factors in the overall. Polo and domestic scholars $[28,29]$ have shown that nerves, blood vessels, and muscle tissue have the same adaptation and regeneration potential just like the osteocyte. Striated muscle cells which have stopped regenerating and splitting in adult tissue, differentiated into muscle stem cells along with the proliferation of stellate cells, and finally formed the new muscle tissue in the slow pulling process. The research has shown that slow pulling process can also induce the regeneration of new nerve tissue [30]. Thus, limb lengthening is a combination of modern histology, biochemistry, and other systemic factors which influence each other. Its meaning based on the concept DO has a new extension, which should be the regeneration and rebuilding of limb composite tissue under a slow pulling process, namely, distraction histogenesis (DH).

In limb lengthening surgery, the speed and time of lengthening process, the site and method of osteotomy, patient age, and other factors will affect the bone healing process. First, the extension rate is one of the most important factors which influence bone healing process [31]. A large number of clinical and animal experiments confirmed that $1.0 \mathrm{~mm} / \mathrm{d}$ is the most reasonable and beneficial extension rate to the healing of bone and soft tissue adaptation. Second, the osteotomy site is also one of the most important factors 
which affect bone healing process. Due to the ability of blood supply and bone formation, different osteotomy sites have different bone osteotomy healing rate. In metaphyseal extension, the bone formation is faster because of the rich blood supply, while the fixture is easy to lose, which have serious impact on joint function and even cause permanent barriers. Backbone osteotomy is far away from the joint, which has light effect on the joint in the lengthening process, and the function of joint can be restored through the exercise. Because of the poor blood circulation here and the smaller diameter of bone, the healing time and fixing time should be increased. In comparison, the backbone of the bone ends is the ideal osteotomy site. Due to the osteotomy line which is farther away from the joint and has light effect on the joint, the change of the joint function in the lengthening process can be restored through exercise after surgery. Besides, the blood circulation here is closed to the bone end and the osteogenesis rate is faster than that of the backbone. Third, osteotomy method also affects bone healing of extension area. Frierson et al. [32] compared different osteotomy method and found that the simple cortex osteotomy has no significant differences with the common osteotomy. Fourth, bone healing can be affected when the delay extension or immediate extension method is used. Yasui et al. [33] have proved that the delay extension method is superior to immediate extension because the blood can be rebuilt and the soft tissue damaged after osteotomy surgery can be restored in the delay extension process.

The Alg/nHAC composite actually promotes the Ilizarov distraction osteogenesis and there maybe two reasons as follows. On one hand, nHAC composite can promote bone healing according to the research done before [25]. The microstructure of nHA may increase surface areas of implant. The microstructured calcium phosphate materials could concentrate more proteins, which may influence the attachment, proliferation, and differentiation of cells. These proteins may include bone-inducing proteins, which could differentiate inducible cells to osteogenic cells that form inductive bone. On another hand, the introduction of algorithm which stabilizes collagen as a cross-linker and preserves its helical structure creates a favorable microenvironment for the regeneration of tissue.

In order to promote bone healing, great amounts of researches had been done [34-38]. By the development of the modern medical technology, minimally invasive technology has aroused people's attention. The combination of clinical treatment and minimally invasive technology is promising. All in all, a further study about DO is rather necessary.

\section{Conclusion}

In this study, the liquid $\mathrm{Alg} / \mathrm{nHAC}$ was injected into the extension area of tibia. The group which was injected into the liquid composite has more regenerated calluses than the control group through general observation and histological observation. The X-ray observation showed that the high density area in the experimental group is superior to the control group in different period. The results of bone density test and biomechanical test also demonstrated that the degree of bone healing and the strength of bone are much more better than the control group. Alg/nHAC was an ideal material for limb lengthening. The present study demonstrates that the injection of liquid calcium alginate/nHAC composites can significantly promote distraction osteogenesis. Alginate/nHAC is promising to be used for clinical application to solve the healing problem of backbone osteotomy and the fixing problem of metaphyseal backbone which has bad effect on the closed joint and causes complication.

\section{Conflict of Interests}

The authors declare that there is no conflict of interests regarding the publication of this paper.

\section{References}

[1] M. Kenawey, C. Krettek, E. Liodakis, U. Wiebking, and S. Hankemeier, "Leg lengthening using intramedullay skeletal kinetic distractor: results of 57 consecutive applications," Injury, vol. 42, no. 2, pp. 150-155, 2011.

[2] R. M. Olabisi, T. M. Best, C. Hurschler, R. Vanderby, and K. J. Noonan, "The biomechanical effects of limb lengthening and botulinum toxin type A on rabbit tendon," Journal of Biomechanics, vol. 43, no. 16, pp. 3177-3182, 2010.

[3] A. Hernandez-Fernandez, R. Vélez, F. Soldado et al., "Effect of administration of platelet-rich plasma in early phases of distraction osteogenesis: an experimental study in an ovine femur model," Injury: International Journal of the Care of the Injured, vol. 44, no. 7, pp. 901-907, 2013.

[4] A. M. Tuzuner-Oncul and R. S. Kisnisci, "Response of ramus following vertical lengthening with distraction osteogenesis," Journal of Cranio-Maxillofacial Surgery, vol. 39, no. 6, pp. 420424, 2011.

[5] A. H. Simpson and J. Kenwright, "Fracture after distraction osteogenesis," Journal of Bone and Joint Surgery B, vol. 82, no. 5, pp. 659-665, 2000.

[6] D. Zarzycki, M. Tesiorowski, M. Zarzycka, W. Kacki, and B. Jasiewicz, "Long-term results of lower limb lengthening by the Wagner method," Journal of Pediatric Orthopaedics, vol. 22, no. 3, pp. 371-374, 2002.

[7] V. Antoci, C. M. Ono, V. Antoci Jr., and E. M. Raney, "Bone lengthening in children: how to predict the complications rate and complexity?" Journal of Pediatric Orthopaedics, vol. 26, no. 5, pp. 634-640, 2006.

[8] D. Paley, "Problems, obstacles, and complications of limb lengthening by the Ilizarov technique," Clinical Orthopaedics and Related Research, no. 250, pp. 81-104, 1990.

[9] F. Launay, R. Younsi, M. Pithioux et al., "Fracture following lower limb lengthening in children: a series of 58 patients," Orthopaedics \& Traumatology: Surgery \& Research, vol. 99, no. 1, pp. 72-79, 2013.

[10] P. H. Thaller, J. Fürmetz, F. Wolf et al., "Limb lengthening with fully implantable magnetically actuated mechanical nails (PHENIX1)-Preliminary results," Injury: International Journal of the Care of the Injured, vol. 45S, pp. S60-S65, 2014.

[11] L. Yang, G. Cai, L. Coulton, and M. Saleh, "Knee joint reaction force during tibial diaphyseal lengthening: a study on a rabbit model," Journal of Biomechanics, vol. 37, no. 7, pp. 1053-1059, 2004 . 
[12] X. M. Li, C. A. Van Blitterswijk, Q. L. Feng, F. Z. Cui, and F. Watari, "The effect of calcium phosphate microstructure on bone-related cells in vitro," Biomaterials, vol. 29, no. 23, pp. 3306-3316, 2008.

[13] A. I. Rodrigues, M. E. Gomes, I. B. Leonor et al., "Bioactive starch-based scaffolds and human adipose stem cells are a good combination for bone tissue engineering," Acta Biomaterialia, vol. 8, no. 10, pp. 3765-3776, 2012.

[14] Y. Liu, J. Lim, S.-H. Teoh et al., "Review: development of clinically relevant scaffolds for vascularised bone tissue engineering," Biotechnology Advances, vol. 31, no. 5, pp. 688-705, 2013.

[15] X. M. Li, X. H. Liu, W. Dong et al., "In vitro evaluation of porous poly(L-lactic acid) scaffold reinforced by chitin fibers," Journal of Biomedical Materials Research B Applied Biomaterials, vol. 90, no. 2, pp. 503-509, 2009.

[16] Y. Deng, H. Wang, L. Zhang et al., "In situ synthesis and in vitro biocompatibility of needle-like nano-hydroxyapatiteinagargelatinco-hydrogel," Materials Letters, vol. 104, pp. 8-12, 2013.

[17] X. M. Li, H. F. Liu, X. F. Niu et al., "Osteogenic differentiation of human adipose-derived stem cells induced by osteoinductive calcium phosphate ceramics," Journal of Biomedical Materials Research B Applied Biomaterials, vol. 97, no. 1, pp. 10-19, 2011.

[18] M. N. Salimi and A. Anuar, "Characterizations of biocompatible and bioactive hydroxyapatite particles," Procedia Engineering, vol. 53, pp. 192-196, 2013.

[19] X. M. Li, X. H. Liu, M. Uo, Q. L. Feng, F. Z. Cui, and F. Watari, "Investigation on the mechanism of the osteoinduction for calcium phosphate," Bone, vol. 43, supplement 1, pp. S111S112, 2008.

[20] X. M. Li, Q. L. Feng, W. J. Wang, and F. Z. Cui, "Chemical characteristics and cytocompatibility of collagen-based scaffold reinforced by chitin fibers for bone tissue engineering," Journal of Biomedical Materials Research B Applied Biomaterials, vol. 77, no. 2, pp. 219-226, 2006.

[21] X. M. Li, Q. L. Feng, X. H. Liu, W. Dong, and F. Cui, "Collagenbased implants reinforced by chitin fibres in a goat shank bone defect model," Biomaterials, vol. 27, no. 9, pp. 1917-1923, 2006.

[22] Y.-C. Chiu, M.-H. Cheng, S. Uriel, and E. M. Brey, "Materials for engineering vascularized adipose tissue," Journal of Tissue Viability, vol. 20, no. 2, pp. 37-48, 2011.

[23] X. M. Li, Q. L. Feng, Y. F. Jiao, and F. Z. Cui, "Collagenbased scaffolds reinforced by chitosan fibres for bone tissue engineering," Polymer International, vol. 54, no. 7, pp. 10341040, 2005.

[24] G. Chen, J. Tanaka, and T. Tateishi, "Osteochondral tissue engineering using a PLGA-collagen hybrid mesh," Materials Science and Engineering C, vol. 26, no. 1, pp. 124-129, 2006.

[25] X. M. Li, Q. L. Feng, and F. Z. Cui, "In vitro degradation of porous nano-hydroxyapatite/collagen/PLLA scaffold reinforced by chitin fibres," Materials Science and Engineering C, vol. 26, no. 4, pp. 716-720, 2006.

[26] A. D. Kanellopoulos and P. N. Soucacos, "Management of nonunion with distraction osteogenesis," Injury, vol. 37, supplement 1, pp. S51-S55, 2006.

[27] G. A. Ilizarov, "Clinical application of the tension-stress effect for limb lengthening," Clinical Orthopaedics and Related Research, no. 250, pp. 8-26, 1990.

[28] A. Polo, R. Aldegheri, A. Zambito et al., "Lower-limb lengthening in short stature. An electrophysiological and clinical assessment of peripheral nerve function," Journal of Bone and Joint Surgery B, vol. 79, no. 6, pp. 1014-1018, 1997.
[29] K. Huang, Y. Zeng, H. Xia, and C. Liu, "Alterations in the biorheological features of some soft tissues after limb lengthening," Biorheology, vol. 35, no. 4-5, pp. 355-363, 1998.

[30] G. A. Ilizarov, Transosseous Osteosynthesis: Theoretical and Clinical Aspects of Regeneration and Growth of Tissue, vol. 1, Springer, Berlin, Germany, 1992.

[31] S. H. White and J. Kenwright, "The importance of delay in distraction of osteotomises," Orthopedic Clinics of North America, vol. 569, no. 4, pp. 569-579, 1991.

[32] M. Frierson, K. Ibrahim, M. Boles, H. Bote, and T. Ganey, "Distraction osteogenesis: a comparison of corticotomy techniques," Clinical Orthopaedics and Related Research, no. 301, pp. 19-24, 1994.

[33] N. Yasui, H. Kojimoto, K. Sasaki, A. Kitada, H. Shimizu, and Y. Shimomura, "Factors affecting callus distraction in limb lengthening," Clinical Orthopaedics and Related Research, no. 293, pp. 55-60, 1993.

[34] B. Kassis, C. Glorion, W. Tabib, O. Blanchard, and J. Pouliquen, "Callus response to micromovement after elongation in the rabbit," Journal of Pediatric Orthopaedics, vol. 16, no. 4, pp. 480485, 1996.

[35] K. S. Eyres, M. Saleh, and J. A. Kanis, "Effect of pulsed electromagnetic fields on bone formation and bone loss during limb lengthening," Bone, vol. 18, no. 6, pp. 505-509, 1996.

[36] X. M. Li, H. F. Liu, X. F. Niu et al., "The use of carbon nanotubes to induce osteogenic differentiation of human adipose-derived MSCs in vitro and ectopic bone formation in vivo," Biomaterials, vol. 33, no. 19, pp. 4818-4827, 2012.

[37] P. M. Van Roermound, B. M. Ter Haar Romeny, and T. Sakou, "Bone growth and remodeling," Journal of Bone and Mineral Research, vol. 19, no. 6, pp. 84-88, 1997.

[38] X. M. Li, L. Wang, Y. B. Fan, Q. L. Feng, F. Z. Cui, and F. Watari, "Nanostructured scaffolds for bone tissue engineering," Journal of Biomedical Materials Research A, vol. 101A, no. 8, pp. 24242435, 2013. 

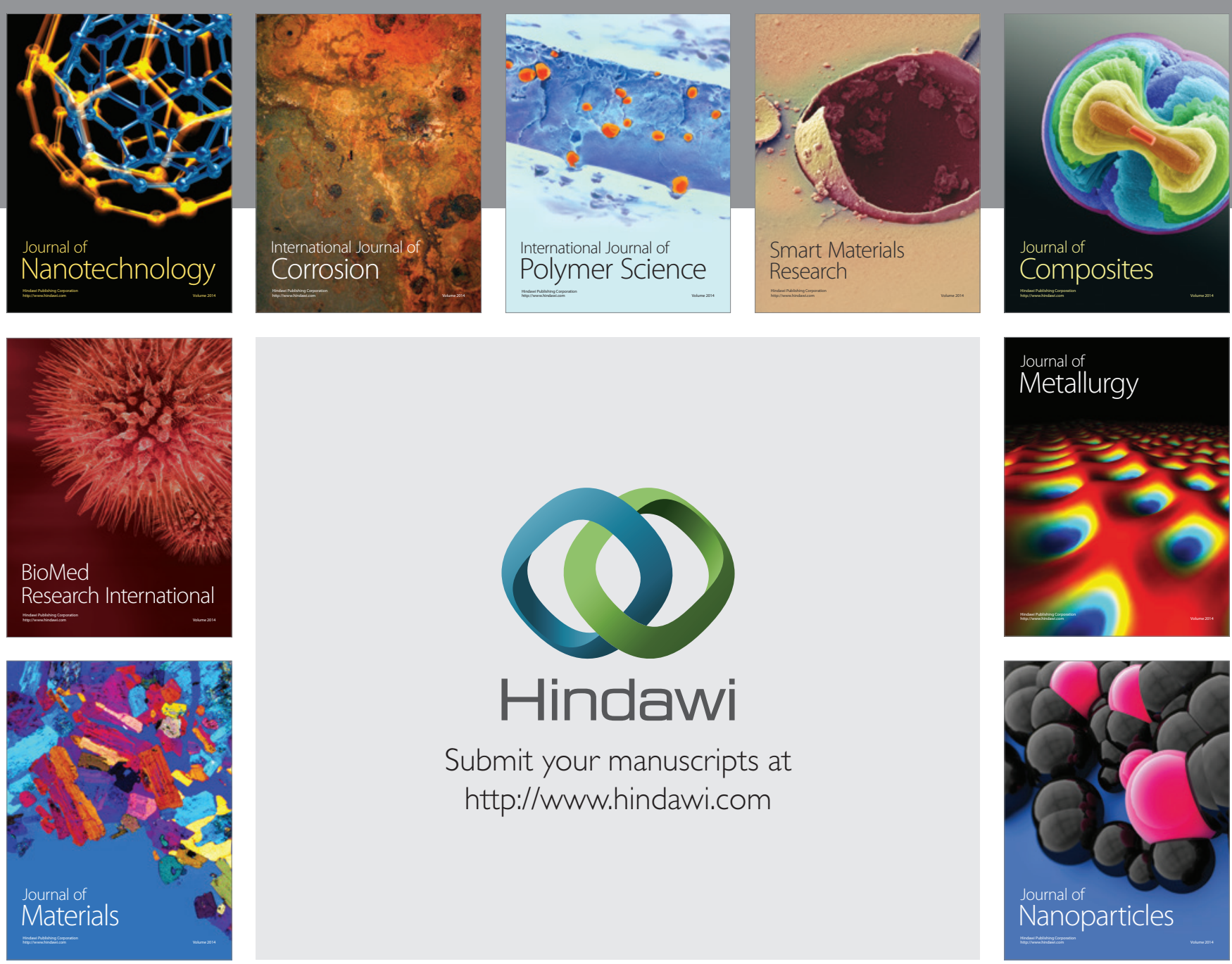

Submit your manuscripts at http://www.hindawi.com
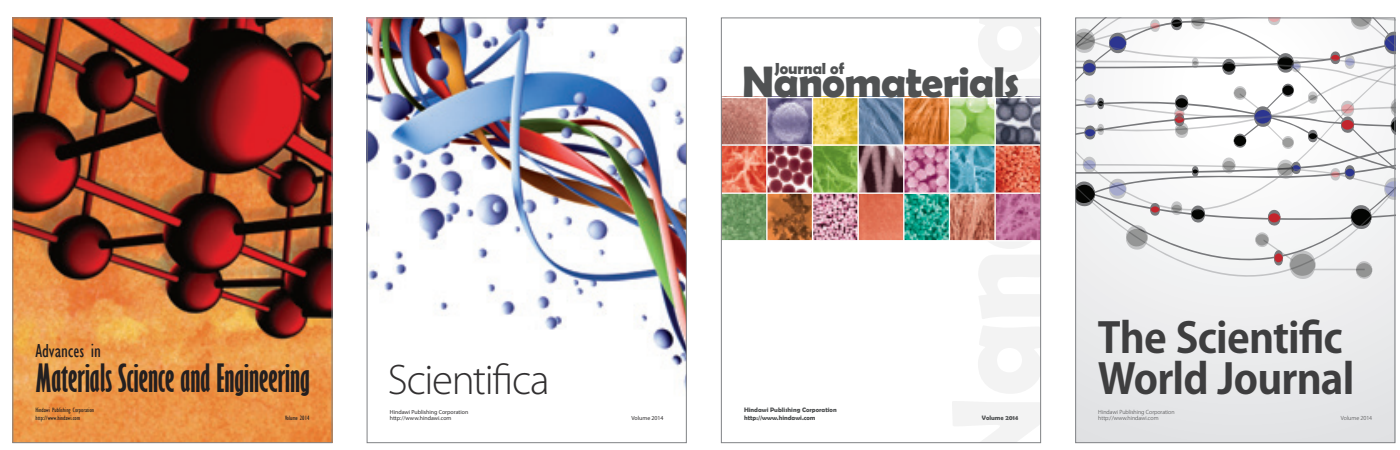

\section{The Scientific World Journal}
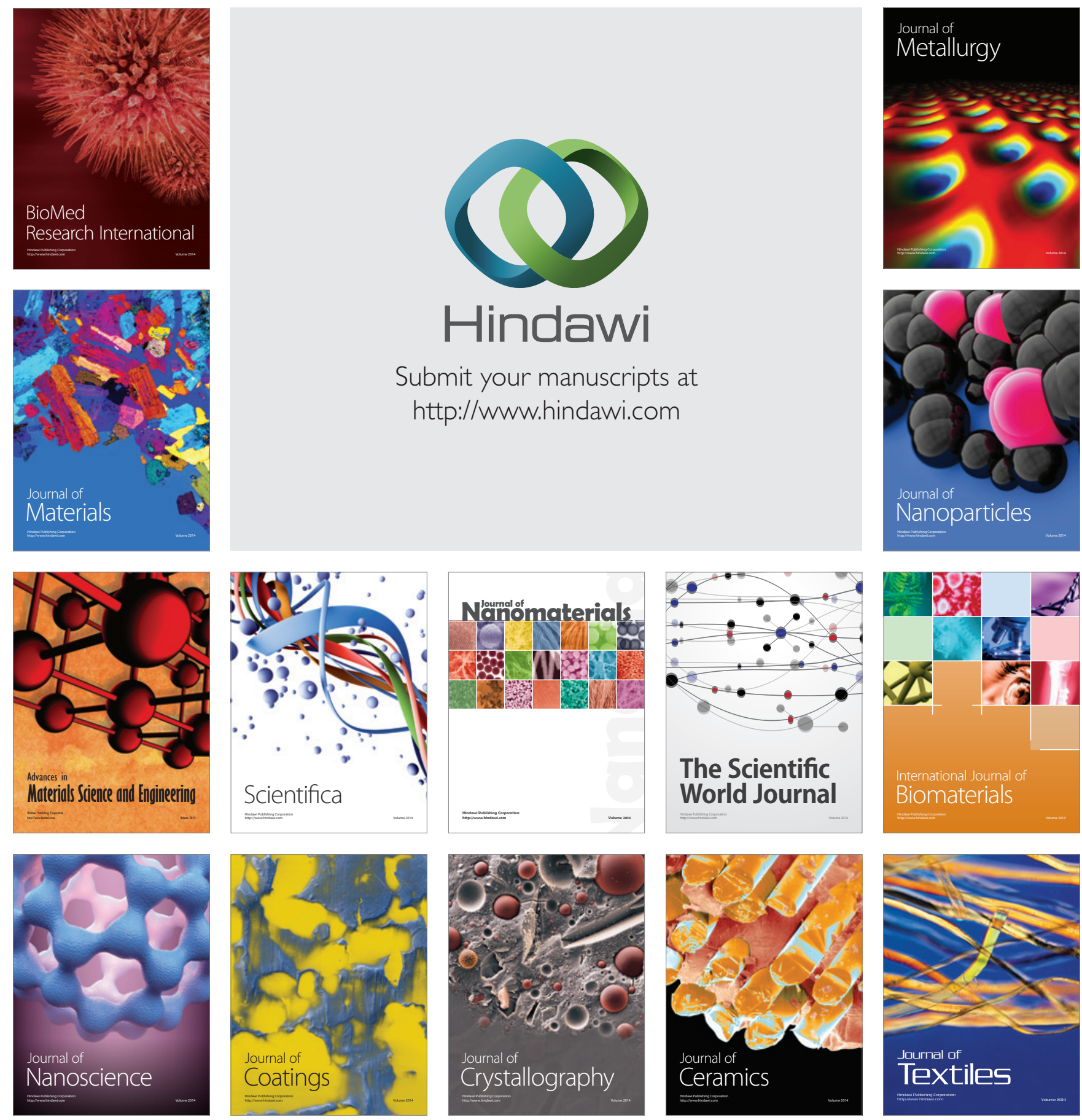